\title{
THE PERSON-CASE CONSTRAINT: A MORPHOLOGICAL CONSENSUS
}

\author{
Jelena Runić, University of Connecticut
}

The Problem - The Person-Case Constraint (PCC), attested in a number of heterogeneous languages, forbids the combination of the $3^{\text {rd }}$ person dative with the $1^{\text {st }}$ or $2^{\text {nd }}$ person accusative within an argument clitic cluster (the weak PCC, cf. (1a)), as well as the combination of the 1st and 2 nd person co-argument clitics (the strong PCC, cf. (1b, c)):

(1) a. *A en Josep, me/te li va recomanar la Mireia.

to the Josep me/you.1/2ACC him.3DAT recommended the Mireia

'She (Mireia) recommended me/you to him (Josep)' [Catalan, Bonet 1991: 178]

b. *O Kostas mu se sístise.

the Kostas me.1GEN you.2ACC introduced

'Kostas introduced you to me'

c. ${ }^{*} \mathrm{O}$ Kostas su me sístise.

the Kostas you.2GEN me.1ACC introduced

'Kostas introduced me to you'

[Greek, Bonet 1991: 178]

As far as Slavic languages are concerned, researchers agree that languages with verbal clitics, Bulgarian and Macedonian, are subject to the PCC. Nevertheless, the existence of PCC effects in Slavic languages with sentential/second position clitics $(\mathrm{Cl} 2)$ has remained controversial (yes in Czech for Béjar \& Řezáč 2003; Bhat \& Šimík 2009; Medová 2009; Sturgeon et al. 2010, i.a.; no in Czech and Serbian/Croatian (SC) for Haspelmath 2004; Migdalski 2006; Hana 2007, i.a.). In this talk, I provide a unified analysis accounting for both the presence and absence of the PCC in Slavic $\mathrm{Cl} 2$ languages. Based on idiolectal variations found in the data, I argue for a morphological filter-based approach that can account for these variations. Further, I extend the analysis to Romance and Greek.

The Data - The results are based on the data collected from 53 linguistic consultants, speakers of $\mathrm{SC}$, Slovenian, Czech and Slovak, all $\mathrm{Cl} 2$ languages. I conducted a grammaticality judgment task, in which 53 participants were asked to mark (a) and (b) examples in (2) and (3) as grammatical or semi/ungrammatical sequences. PCC effects have been attested with 15 (out of 19) of the consultants in SC, 10 (out of 12) in Slovenian, 11 (out of 14) in Czech, and 8 (out of 8) in Slovak. In short, PCC effects are found with most (though not all) speakers of $\mathrm{Cl} 2$ languages, both with the weak PCC (cf. (2)) and the strong PCC (cf. (3)), exemplified with SC in (2) and (3):

(2) a. Toplo mu/joj te preporučujem.

$[\mathrm{SC}]$

warmly him/her.3DAT you.2ACC recommend.1SG

'I warmly recommend you to him/her.'

b.??(*) Toplo mu/joj me preporučuješs.

warmly him/her.3DAT me.1ACC recommend.2SG

'You warmly recommend me to him/her.'

(3) a. Toplo mi te preporučuje.

warmly me.1DAT you.2ACC recommends

'He warmly recommends you to me.'

b.??(*) Toplo ti me preporučuje. certainly you.2DAT me.1ACC recommends

'He warmly recommends me to you.' 
The Analysis - Previously unnoticed is the pattern in (2) and (3) found in SC, Slovak, and Slovenian, confirmed by the majority of the consultants. This pattern shows that the PCC is actually operative since accusative clitics are fully acceptable in clusters with the $2^{\text {nd }}$ person accusative (cf. (2a), (3a)), while clusters with the $1^{\text {st }}$ person accusative are degraded (cf. (2b), (3b)). Similar results have been reported for Czech (Sturgeon et al. 2010, i.a.) and Romanian (Nevins 2007).

Much of the more recent proposals on the PCC are put forward in the Agree framework of Chomsky (2001) and his subsequent work. Thus, the PCC emerges as a violation of the incompatibility of person and number features checking requirements within the same agreement domain. In order to account for the PCC in Slavic, Migdalski (2006) follows the standard syntactic account concerning the incompatibility of person and number feature checking. This account requires that the accusative clitic must be underspecified for person features (Anagnostopoulou 2003). Consequently, the accusative must be a $3^{\text {rd }}$ person in Macedonian, as illustrated by (4c). The derivation crashes when the accusative is a $2^{\text {nd }}$ person (cf. (4a)). Since the $2^{\text {nd }}$ person is specified for the feature [Person], the convergent derivation has to involve long, non-clitic full pronominal form (4b).
(4) a. *Jas im te preporučavam [Macedonian, Migdalski 2006: 199]
I them.3DAT you.2ACC recommend
b. Jas te preporučavam na niv
I you.2ACC recommend them.3DAT
'I am recommending you to them.'
c. Jas im ja preporučavam
I them.3DAT her.3ACC recommend
'I am recommending her to them

As for SC, Migdalski (2006) contends, on the basis of clusters containing a $2^{\text {nd }}$ person accusative (cf. (2a), (3a)), that the PCC is not operative in this language. The difference between SC and Macedonian, according to Migdalski (2006), lies in the different syntactic positioning of clitics between languages with verbal clitics (Macedonian) and Cl2 languages (SC). Specifically, following Bošković (2001), Migdalski (2006) claims that (verbal) clitics in Macedonian are all adjoined to a single head, whereas $(\mathrm{Cl} 2)$ clitics in $\mathrm{SC}$ are located in different syntactic positions. This explains why there is a feature-checking mismatch in Macedonian, unlike SC, where all clitics can check their features in separate projectons, the derivaton thus being able to converge.

Nonetheless, the asymmetry between (a) and (b) examples in (2) and (3) in SC poses a problem for Migdalski's (2006) account. If, as Migdalski argues, SC is not subject to the PCC due to the fact that clitics do not cluster together but target specifiers of different projections (Bošković 2001), a mismatch in the checking requirements between the $1^{\text {st }}$ and $2^{\text {nd }}$ person would not emerge and (2b) and ( $3 b)$ would be predicted to be grammatical. Nevertheless, the result is undesirable as the derivation crashes when the $1^{\text {st }}$ person accusative is present in the Agree domain.

In this talk, I offer an alternative analysis that can account not only for the difference in PCC effects between the 1st and 2nd person in (2) and (3) above but can also explain idiolectal variations found in the data. Specifically, I argue that the PCC arises in the Morphology as a consequence of illicit morphological feature combinations. The data in (2)-(3) indicate that in ditransitive clitic constructions consisting of a Theme and a Recipient, the combination of the 1st person Theme is excluded (cf. (2b), (3b)), whereas the combination of the 2 nd person Theme is acceptable (cf. (2a), (3a)). In this connection, there is a robust cross-linguistic generalization 
showing harmonic alignment between the person scale and the semantic role scale (Aissen 1999, i.a.). On the person scale, 1st person outranks 2 nd person and 3rd person (5a). Similarly, on the semantic role scale, Agent outranks Recipient, which in turn outranks Theme/Patient (5b):
(5) a. $1 \mathrm{st}>2^{\text {nd }}>3 \mathrm{rd}$
b. Agent $>$ Recipient $>$ Theme/Patient

(5) means that in ditransitive constructions the (highest) 1 st or 2 nd person is typically associated with the (highest) roles, Agent and Recipient. The data in (2)-(3) show this is the case, as the 1st person in the degraded clusters is associated with the Theme $(2 b, 3 b)$. This observation is similar to Haspelmath's (2004) claim that the PCC is sensitive to the alignment between the person scale and the semantic role scale. Contrary to Haspelmath's (2004) functionalist approach, the validity of which is assessed through the diachronic usage of clitic combinations, I argue that this harmonic alignment can be formally captured by means of morphological output filters, arranged in an implicational hierarchy. Morphological filters (or constraints) represent innate combinations of morphological features that have to be de-activated on the basis of positive evidence in order to surface (Calabrese 1995; Noyer 1997). These filters are active in the morphological component of the grammar once the Syntax generates the structure and sends it to the PF for morphological and phonological processing. First, assuming that the 1st person is featurally represented as [+Author] (Halle 1997), while the Theme in Slavic contains the feature [+Accusative], I propose a morphological output filter that bans the combination of morphological features in argument clitic clusters (cf.(2b), (3b)), as in (6):

(6) $*[\mathrm{Arg} \mathrm{Cl} \alpha \operatorname{Arg~Cl~} \beta]$ if $\alpha$ [+Author +Accusative] \& $\beta[$-Author + Dative]

Consequently, when the 1 st person clitic bearing the features [+Author +Accusative] occurs with a 2nd or 3rd person clitic with the features [-Author +Dative], the structure will be illicit in the Morphology. A similar ban on feature co-occurrence is imposed in Western Romance, in which, unlike the [+Author] feature in Slavic, the forbidden combination holds for both the 1st and 2nd person Theme, featurally represented as [+Participant] (Halle 1997) (cf. (1a) in Catalan). For Western Romance, I propose the following filter:

(7) $*[\operatorname{Arg~Cl} \alpha \operatorname{Arg~Cl} \beta]$ if $\alpha$ [+Participant +Accusative $] \&$ [ \pm Participant + Dative $]$

Overall, the PCC filter is parameterized for the features of the Theme, the filter being active when either [+Author] or [+Participant] are not highest on the semantic role scale due to the absence of harmonic alignment between the two scales in question.

Based on the top-down implicational hierarchy established among the current microvariations of the PCC, I postulate three filters with a filter for Slavic (and Romanian) being deepest/lowest on the hierarchy, as in (8) below. Filters are typically arranged in hierarchies according to their complexity, the most complex filter being lowest/deepest in this hierarchy (Calabrese 1995; Noyer 1997). In terms of the implicational hierarchy in (8), it can be concluded that if a language has strong PCC effects (e.g., Greek), banning the1st/2nd person Theme/accusative with a 1st/2nd and 3rd person Recipient/dative, it is automatically assumed that the other two lower filters in (8) are active as well. Thus, the lowest filter is highly costly (complex) because its deactivation requires that the other two filters above it be deactivated.

(8) $*[\operatorname{Arg~Cl} \alpha \operatorname{Arg~ClB}]$ if

$\alpha[+$ Participant + Accusative $] \& \beta[ \pm$ Participant + Dative/+Genitive $]$

(Greek, French, Italian)

$\alpha$ [+Participant +Accusative] \& $\beta$ [- Participant + Dative]

$\alpha[+$ Author + Accusative $] \& \beta[$-Author + Dative $]$

(Catalan, Spanish)

(Slavic, Romanian) 
Whenever positive evidence contradicts a particular filter, this filter (and all filters above it) will be deactivated. This explains why some Slavic speakers do not find PCC effects at all. Since such clitic combinations are rare in the input, only some speakers de-activate the lowest filter and all the filters above it, which in turn explicates the partial absence of PCC effects in C12 Slavic languages.

Conclusions - Microvariational and idiolectal differences with respect to the PCC are accounted for by an implicational hierarchy of illicit morphological feature combinations. According to this hierarchy, the PCC is parameterized for the features [Author] in Slavic and [Participant] in Western Romance and Greek, and the PCC can be de-activated whenever positive evidence contradicts a particular filter.

\section{References}

Aissen, Judith (1999). Markedness and subject choice in Optimality Theory. NLLT 17: 673-711. Anagnostopoulou, Elena (2003). The Syntax of Ditransitives. Evidence from Clitics. Mouton de Gruyter.

Béjar, Susana \& Milan Řezáč (2003). Person licensing and the derivation of PCC effects. In Pérez-Leroux, A. T. \& Y. Roberge (Eds.), Romance Linguistics: Theory and Acquisition: 49-62.

Bhatt, Rajesh \& Radek Šimík (2009). Variable Binding and the Person-Case Constraint. Paper presented at the 25th Annual Meeting of the Israel Association for Theoretical Linguistics (IATL 25), Ben Gurioon University of the Negev, 12-13 October Beer Sheva, Israel.

Bonet, Eulàlia (1991). Morphology after Syntax: Pronominal Clitics in Romance. Doctoral dissertation, MIT.

Calabrese, Andrea (1995). A constraint-based theory of phonological markedness and simplification procedures. Linguistic Inquiry 26: 373-463.

Chomsky, Noam (2001). Minimalist inquiries: The framework. In R. Martin, D. Michaels \& J. Uriagereka (eds.), Step by step: Essays on minimalist syntax in honor of Howard Lasnik. Cambridge, Mass.: MIT Press, 89-156.

Halle, Morris (1997). Distributed Morphology: Impoverishment and Fission. In B. Bruening, Y. Kang, and M. McGinnis (eds.), Papers at the Interface, Vol 30, MIT Working Papers in Linguistics, 425-449.

Hana, Jiri (2007). Czech Clitics in Higher Order Grammar. Doctoral dissertation. Ohio State University.

Haspelmath, Martin (2004). Explaining the Ditransitive Person-Role Constraint: a usage-based account. Constuctions 2/2004, 49 pp.

Medová, Lucie (2009). PCC effects in Czech. Paper presented at the Formal Approaches to Slavic Linguistics (FASL) 18.

Migdalski, Krzysztof (2006). The Syntax of Compound Tense in Slavic. Doctoral Dissertation. University of Tilburg.

Nevins, Andrew (2007). The representation of third person and its consequences for personcase effects. Natural Language \& Linguistic Theory 25: 273-313.

Noyer, Rolf (1997). Features, positions, and affixes in autonomous morphological structure. New York \& London: Garland Publishing.

Sturgeon, Anne \& Boris Harizanov \& Maria Polinsky \& Ekaterina Kravtchenko \& Carlos Gómez Gallo \& Lucie Medová \& Vaclav Koula (2010). Revisiting the Person Case Constraint in Czech. Paper presented at Formal Approaches to Slavic Linguistics 19. 